\title{
Gastric mucosal barrier: barrier to hydrogen ions imparted by gastric surfactant in vitro
}

\author{
B A Hills, C A Kirwood
}

\begin{abstract}
A simple experiment is described which shows how the highly surface active ingredient of gastric surfactant (DPPC) can be deposited on a filter paper to reduce the rate of transmission of hydrogen ions by one to two orders of magnitude. This finding is compatible with previous studies implying that the hydrophobic layer of surface active phospholipid provides the gastric mucosal barrier as a distinct physical entity.

(Gut 1992; 33: 1039-1041)
\end{abstract}

The mechanism of gastric mucosal protection remains a controversial issue for which many theories have been proposed,' but much evidence still favours a physical protective lining as originally envisaged in Davenport's concept ${ }^{2}$ of a 'gastric mucosal barrier' which impedes the diffusion of hydrogen ions. Interest in this concept has been rekindled by the observation that the normal gastric mucosa is hydrophobic. ${ }^{3}$

Hydrophobicity is often used by those studying the protection of non-biological surfaces from acids as a convenient indication of the retention of adsorbed corrosion inhibitors, these being almost invariably surfactants with many ${ }^{4}$ not unlike the surface active phospholipid found in the lung. It was therefore very interesting to find surface active phospholipid in gastric juice and in 'light scrapings' of mucosal epithelium..$^{56}$ Moreover, mucosal hydrophobicity was greatly reduced by the common 'barrier breakers,", these either combining with surface active phospholipid chemically - for example, aspirin or bile salts, or acting as a solvent such as ethanol. There are now a number of studies confirming that supplementation of gastric surfactant offers mucosal protection..$^{7-10}$

Recent morphological studies ${ }^{1011}$ have also shown a physical basis for a gastric mucosal barrier in the form of oligolamellar surface active phospholipid, either providing the intergranular matrix material of the mucus lining the lumen of the stomach or as a thicker oligolamellar coating of surface active phospholipid on deeper mucus free epithelial surfaces also exposed to the corrosive environments. These include oxyntic ducts and the canaliculi of parietal cells.

Although there is much indirect evidence

Department of Physiology, University of New England, Armidale, NSW, Australia B A Hills

C A Kirwood

Correspondence to: Prof B A Hills, Dept of Physiology, University of New England, Armidale, NSW 2351, Australia.

Accepted for publication 11 November 1991 which is supportive, it is still necessary to prove directly that adsorbed surface active phospholipid can inhibit the transmission of hydrogen ions. An elegant experiment was recently carried out upon necturus gastric mucosa ex vivo by Kiviluoto et $a l^{12}$ who showed that the administration of surface active phospholipid increased apical cell membrane resistance to hydrogen ions by $108 \%$. If it is indeed the surface active phospholipid which is providing a barrier and not some other agent present in the biological milieu, however, then surface active phospholipid should also be able to do the same in a purely in vitro system. This study describes a very simple experiment to test this concept in vitro devoid of the many possible factors which could complicate results obtained in vivo.

\section{Methods}

\section{MATERIALS}

A simple filter paper (Gelman PEM) with a small pore size $(75 \AA)$ was selected as a basic inert matrix material on which to deposit a surface active phospholipid 'membrane.' This was located in the standard Ussing chamber as used to monitor hydrogen ion transmission through tissue sections (Fig 1). Hydrogen ion transmission rate was measured by placing $\mathrm{pH}$ electrodes on both sides and adding saline to one side and acid $(0.2 \mathrm{~N} \mathrm{HCl})$ to the other side to attain a $\mathrm{pH}$ of 2.0 in order to simulate normal gastric acidity.

Deposition of the highly insoluble surface active phospholipid in the form of L $\alpha$-dipalmitoyl phosphatidylcholine (DPPC, Sigma P6267) as a 'membrane' proved difficult, but could be effected from its suspension in saline $(10 \mathrm{mg} / \mathrm{ml})$ in an ultrasonicator (Laboratory Supply Co, Hicksville, NY, USA. Model 1128PIT) by two methods. Both involved ultrasonicating the filter paper in the surface active phospholipid suspension for 90 minutes at $4^{\circ} \mathrm{C}$ then soaking in the same suspension for 16 hours. By the first technique a high molecular weight, highly water soluble carrier molecule was used in the form of

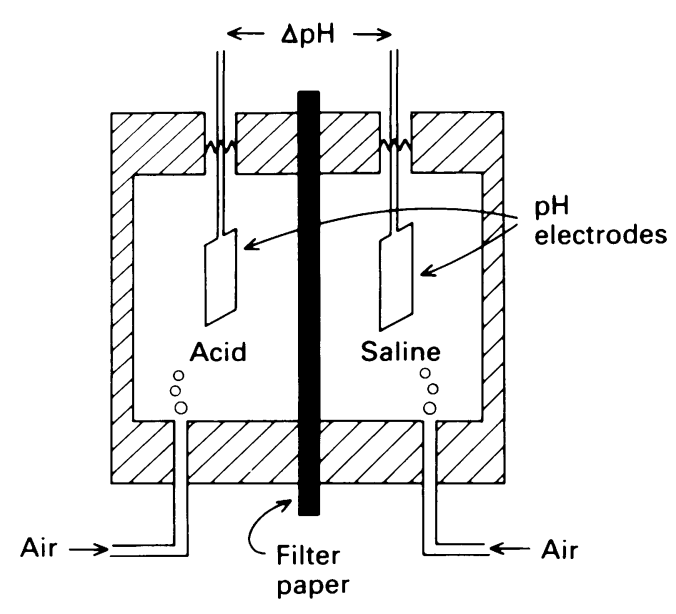

Figure 1: A simple Ussing chamber in which acid $(\mathrm{HCl})$ and saline stirred by air bubbles are initially separated by a filter paper with or without a surface active phospholipid 'membrane' and the $\mathrm{pH}$ in each chamber recorded by electrodes as shown. 


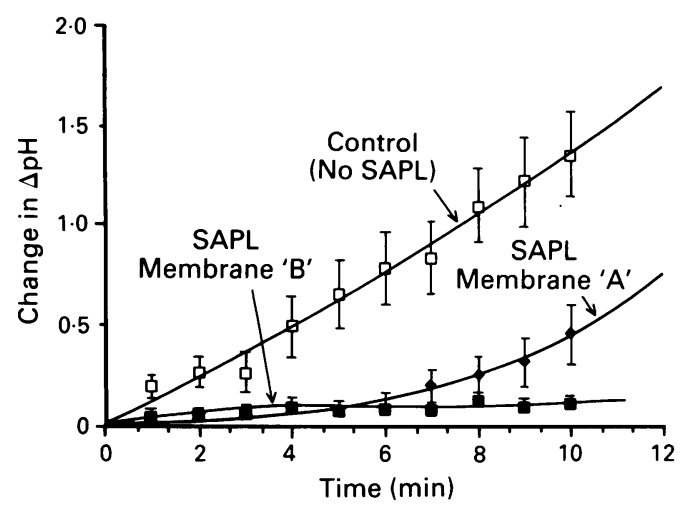

Figure 2: The change in $\Delta p H$, as depicted in Figure 1, for controls having been soaked in hyaluronic acid solution or $\mathrm{Ca} \mathrm{a}^{2+}$ with no surface active phospholipid and for surface active phospholipid 'membranes' deposited on the filter paper either from a surface active phospholipid medium high in calcium ions $(A)$ or from one containing hyaluronic acid $(B)$.

hyaluronic acid (Sigma H538S) for which surface active phospholipid has a reversible chemical affinity. ${ }^{13}$ The hyaluronic acid concentration was $10 \mathrm{mg} / \mathrm{ml}$. To ensure that it was not the hyaluronic acid providing the 'membrane,' surface active phospholipid was also deposited from a $10 \mathrm{mg} / \mathrm{ml}$ suspension of DPPC using raised calcium ions $(100 \mathrm{mM} \mathrm{CaCl})$. Calcium ions are known to accelerate phase equilibration of surfactant in the lung..$^{14}$ All 'membranes' were washed three times in distilled water before use in the Ussing chamber. The control filter papers were similarly treated with $\mathrm{Ca}^{2+}$ or hyaluronic acid alone but omitting surface active phospholipid.

\section{Results}

In the 10 'control' runs the pH in the 'acid' chamber remained constant while the $\mathrm{pH}$ in the other chamber started at $6 \cdot 19$ in all cases and fell rapidly, falling by $1 \cdot 36(0 \cdot 21) \mathrm{pH}$ units $(\mathrm{n}=10)$ in 10 minutes. The fall in $\mathrm{pH}$ with surface active phospholipid 'membranes' present was much slower, falling $0.46(0.15) \mathrm{pH}$ units $(\mathrm{n}=11)$ for surface active phospholipid deposited from the $\mathrm{Ca}^{2+}$ solution and by only $0 \cdot 12(0.04) \mathrm{pH}$ units

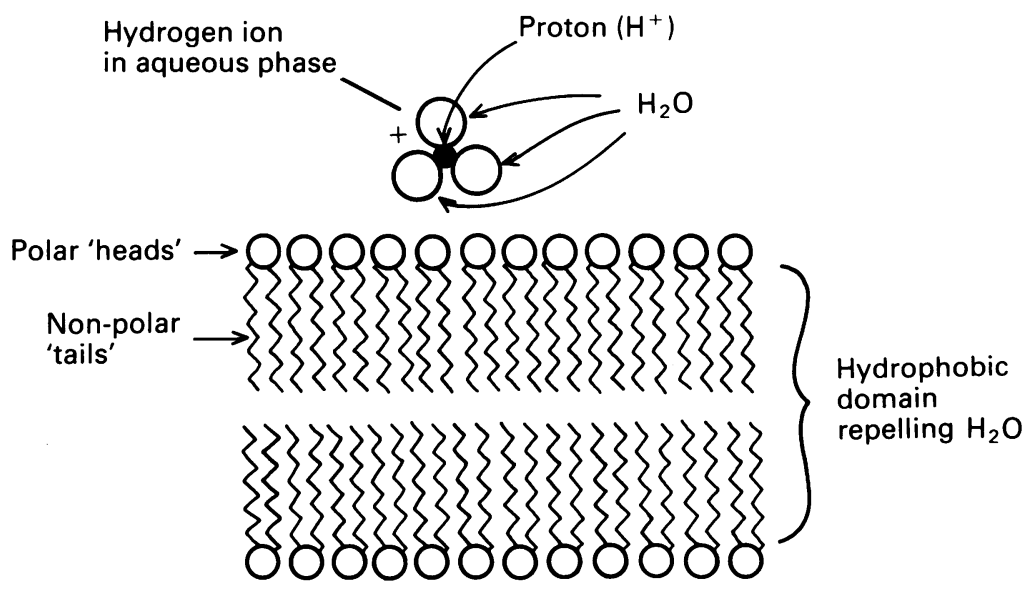

Figure 3: Depicting a simple bilayer of surface active phospholipid only in which the central hydrophobic domain repels any water including the water of hydration which, in any aqueous environment, must surround any atomic particle as highly polarising as a proton in forming the hydrogen ion as $\mathrm{H}\left(\mathrm{H}_{2} \mathrm{O}\right)_{3}^{+}$. $(n=10)$ in 10 minutes for the surface active phospholipid membrane deposited from the hyaluronic acid solution. The relative time courses are shown in Figure 2. Statistical significance for the changes in $\mathrm{pH}$ exceeded $95 \%$ relative to controls for both membranes at each of the $10 \times 1$ minute intervals for which values were recorded and reached $99 \%$ significance by the 10 minute reading. All values quoted are (SD).

\section{Discussion}

The simple experiment described above leaves little doubt that the rate of transmission of hydrogen ions is greatly reduced by a 'membrane' of surface active phospholipid - that is, by the particularly surface active and predominant component $^{5}$ of phospholipid in the stomach. The resistance changes shown in Figure 2 represent one to two orders of magnitude when considering that the results refer to $\mathrm{pH}$ units which are related to hydrogen ion concentration as the logarithm to the base 10 . This result would certainly support the increased resistance found by Kiviluoto et $a l^{12}$ in administering surfactant and, as experiment $B$ used no materials of biological origin, any doubts can be dispelled that surface active phospholipid was not acting as a simple physical barrier.

In many respects the surface active phospholipid 'membrane' can be regarded as a biological membrane without the intercalated protein and hence the ion channels generally associated with it. ${ }^{15}$ Therefore such bilayers found laterally contiguous to an epithelial membrane, ${ }^{10}$ or as a mucous matrix material, "as shown by electronmicroscopy, would impart an effective barrier to hydrogen ion transmission.

The reason why a bilayer of surface active phospholipid should be a barrier to acid is an interesting theoretical question but is probably related to the enormous repulsion for water which the non-polar (fatty acid) ends of the surface active phospholipid molecules exert. ${ }^{16}$ In fact it is essentially this strong repulsion for water which enables phospholipids to form membranes in the first place, escaping the aqueous environment to form a central hydrophobic domain. ${ }^{15}$ Thus it would be anticipated that this domain and, hence, the surface active phospholipid coating would repel the water of hydration of the hydrogen ion $-\mathrm{H}\left(\mathrm{H}_{2} \mathrm{O}\right)_{3}^{+}$. A proton $\left(\mathrm{H}^{+}\right)$is far too strongly polarising to exist in an aqueous environment without binding to water molecules and, in this case, to three of them $^{16}$ as depicted in Figure 3. The same forces would apply to other ions which are hydrated for example, $\mathrm{Na}\left(\mathrm{H}_{2} \mathrm{O}\right)_{7}^{+}$and this would explain their exclusion by the gastric mucosal barrier.

Such a barrier would be broken by solvents for surface active phospholipid, reagents ${ }^{3}$ and phospholipases, ${ }^{13}$ especially phospholipase $\mathrm{A}_{2}$ as secreted by Helicobacter pylori, ${ }^{1+}$ which would explain how these bacteria can act as an 'aggressive agent' while simultaneously reducing mucosal hydrophobicity. ${ }^{17}$

1 Fromm D. Gastric mucosal barrier. In: Johnson LR, ed. Physiology of the gastroentestinal tract. New York: Raven, 1981: $733-45$. 
2 Davenport HW, Warner HA, Code CF. Functional significance of gastric mucosal barrier to sodium. Gastroenterology 1964; 47 : 142-7.

3 Hills BA, Butler BD, Lichtenberger LM. Gastric mucosa barrier: hydrophobic lining to the lumen of the stomach. Am 7 P hysiol 1983; 7: G651-8.

4 Hills BA. What is the true role of surfactant in the lung? Thorax 1981; 36: 1-4.

5 Butler BD, Lichtenberger LM, Hills BA. Distribution of surfactants in the canine GI tract and their ability to lubricate. Am F Physiol 1983; 7: G742-8.

6 Wassef MK, Lin YN, Horowitz MI. Molecular species of phosphatidylcholine from rat gastric mucosa. Biochim Biophys Acta 1979; 573: 222-6.

7 Hills BA, Kirwood CA. Surfactant approach to the gastric mucosal barrier: protection of rats by banana even when acidified. Gastroenterology 1989; 97: 294-303.

8 Swarm RA, Ashley SW, Soybel DI, Ordway FS, Cheung LY. Protective effect of exogenous phospholipid on aspirininduced mucosal injury. Am $\mathcal{F}$ Surg 1987; 153: 48-53.

9 Szelenyi I, Engler H. Cytoprotective role of gastric surfactant in the ethanol-produced gastric mucosal injury in the rat. in the ethanol-produced gastric
Pharmacology 1986; 33: 199-205.
10 Hills BA. A physical identity for the gastric mucosal barrier. Med F A A st 1990; 153: 76-81.

11 Hills BA. A common physical basis for the gastric mucosal barrier and the action of sucralfate. Am f Med 91: (2A) 43-51

12 Kiviluoto $T$, Paimela $\mathrm{H}$, Mustonen $\mathrm{H}$, Kivilaakso $\mathrm{E}$ Exogenous surface-active phospholipid protects necturus gastric mucosa against luminal acid and barrier-breaking agents. Gastroenterology 1991; 100: 38-46.

13 Hills BA. The biology of surfactant. Cambridge: Cambridge University Press, 1988.

14 Raedsch R, Stiehl A, Pohl S, Plachky J. Quantification of phospholipase $\mathrm{A}_{2}$ activity of Campylobacter pylori [Abstract]. Gastroenterology 1989; 96: A478.

15 Singer SJ, Nicolson GL. The fluid mosaic model of the structure of cell membranes. Science 1972; 175: 720-31.

16 Israelachvili JN. Intermolecular and surface forces. London: Academic Press, 1985: 105.

17 Spychal RT, Goggin PM, Marrero JM, Saverymuttu SH, Yu $\mathrm{CW}$, Corbishey CM, et al. Surface hydrophobicity of gastric mucosa in peptic ulcer disease: relationship to gastritis and mucosa in peptic ulcer disease: relationship to gastritis and $1250-4$. 